\title{
Synthesis and Characterization of New Environmentally-Friendly Pigments Based on Cerium Phosphate
}

\author{
Toshiyuki MASUI, Hiroshi TATEGAKI, Shinya FURUKAWA and Nobuhito IMANAKA \\ Department of Applied Chemistry, Faculty of Engineering and Handai Frontier Research Center, Osaka University, \\ 2-1, Yamadaoka, Suita-shi, Osaka 565-0871
}

\author{
リン酸セリウムを母体とする新しい環境調和型顔料の合成とキャラクタリゼーション \\ 増井敏行 · 立垣裕史 ·古川慎也 · 今中信人 \\ 大阪大学大学院工学研究科物質化学専攻, 565-0871 大阪府吹田市山田丘 2-1
}

\begin{abstract}
New yellow-green pigments based on cerium orthophosphate were synthesized by the solid-state reaction in order to develop ecological and environmentally-friendly specific pigments. The pigments were obtained by doping alkaline earth metal ions into a cerium orthophosphate lattice to form their solid solutions. The products were characterized by using X-ray powder diffraction, UV-Vis spectroscopy, Fourier-transform infrared spectroscopy (FT-IR), Raman spectroscopy, and colorimetric assessment. From these results, it has been evidenced that the formation of solid solution is necessary to have color coordinates in the synthesized pigment samples. Since the color of the pigments was almost the same yellow-green in all solid solution samples, the origin of the coloration was attributed to the appearance of the principal broad absorption band corresponding to the $4 \mathrm{f}-5 \mathrm{~d}$ electron transition of $\mathrm{Ce}^{3+}$ and the additional $\mathrm{O}_{2 \mathrm{p}}-\mathrm{Ce}_{4 \mathrm{f}}$ charge transfer transition of $\mathrm{Ce}^{4+}$ by the doping of alkaline earth ion into $\mathrm{CePO}_{4}$ lattice.

[Received August 10, 2004; Accepted October 26, 2004]
\end{abstract}

Key-words: Cerium phosphate, Solid solution, Ecological pigments, Color properties, FT-IR, Raman spectroscopy

\section{Introduction}

Inorganic pigments have been applied in various applications such as paints, ceramics, plastics, enamels, glasses, and so on. ${ }^{1)}$ However, the conventional inorganic pigments for the above applications contain the toxic elements such as $\mathrm{Cd}$, Co, $\mathrm{Cr}, \mathrm{Hg}, \mathrm{Pb}, \mathrm{Sb}$, or Se. Therefore, discovery and development of new and improved inorganic pigments have been desired in order to replace toxic inorganic pigments with more environmentally-friendly pigments or less toxic substances. Although the use of high-performance organic pigments is one way to get several colors, these pigments have some limitations because of thermal and ultraviolet (UV)-ray radiation instabilities. As a work on this line, some new safe inorganic pigments based on metal oxides and compounds have been proposed by several researchers including our group. ${ }^{2)-6)}$ However, only a few new inorganic pigments have been developed in recent decades.

In the present study, new pigments based on cerium orthophosphate have been synthesized and their color properties have been investigated from the viewpoint of possible ecological inorganic pigments. Cerium phosphate $\left(\mathrm{CePO}_{4}\right)$ is a wellknown material that exists in nature as a main component of Monazite minerals and very stable against heat and UV-rays. The pigments presented in this study are inert and safe not to give side effects to the human body, because metal phosphate is a main component of bone and tooth. These pigments can be prepared by a simple solid-state reaction method using the starting materials containing non-toxic elements, and the optical and color properties of $\mathrm{CePO}_{4}$ based pigments have been characterized.

\section{Experimental}

The starting materials used for the synthesis of $\mathrm{CePO}_{4}$ based pigments were $\mathrm{CePO}_{4}$ (High Purity Chemicals, 99.9\%),
$\mathrm{MgCO}_{3}$ (Wako Chemicals, 99.99\%), $\mathrm{CaCO}_{3}$ (Wako Chemicals, 99.99\%), $\mathrm{SrCO}_{3}$ (Wako Chemicals, 99.99\%), $\mathrm{BaCO}_{3}$ (Wako Chemicals, 99.9\%), $\mathrm{ZnCO}_{3} \cdot \mathrm{H}_{2} \mathrm{O}$ (Wako Chemicals, $97 \%$ ), and $\left(\mathrm{NH}_{4}\right)_{2} \mathrm{HPO}_{4}$ (Aldrich, 99.99\%). These materials were thoroughly mixed in a molar ratio of $\mathrm{CePO}_{4}: \mathrm{MCO}_{3}$ : $\left(\mathrm{NH}_{4}\right)_{2} \mathrm{HPO}_{4}=9: 1: 1(\mathrm{M}=\mathrm{Mg}, \mathrm{Ca}, \mathrm{Sr}, \mathrm{Ba}$, and $\mathrm{Zn})$ in an agate mortar for $30 \mathrm{~min}$. The mixtures were calcined at $900^{\circ} \mathrm{C}$ for $12 \mathrm{~h}$ in air atmosphere in an electric resistance furnace increasing the temperature at a rate of $3^{\circ} \mathrm{C} \mathrm{min}^{-1}$. In order to identify the effect of the existence of a $4 \mathrm{f}$ electron in the host phosphate to the hue of the pigments, $\mathrm{Ca}$-, $\mathrm{Sr}-$, and Ba-doped $\mathrm{LaPO}_{4}$ pigments were also synthesized as reference samples in the same procedure for the $\mathrm{CePO}_{4}$-based samples.

The pigments were characterized by X-ray powder diffraction (XRD; Rigaku, Multiflex). The XRD patterns were recorded in the $2 \theta$ range from $10^{\circ}$ to $70^{\circ}$ using $\mathrm{Cu} \mathrm{K} \alpha$ radiation. Optical reflectance, FT-IR, and Raman spectra of the powder were measured with a UV-Vis spectrometer (Shimadzu UV-2450) using barium sulfate as a reference, an FT-IR spectrometer (Bruker TENSOR27), and a Raman spectrometer (Kaiser Optical Systems, Inc., Holoprobe), respectively.

The color properties of the samples were estimated in terms of CIE $L^{*} a^{*} b^{*}$ system with a colorimeter (Minolta, CR-300). The values $a^{*}$ (the axis red-green) and $b^{*}$ (the axis yellowblue) indicate the color hue. The value $L^{*}$ represents the lightness or darkness of the color as related to a neutral grey scale. In the $L^{*} a^{*} b^{*}$ system, it is described by numbers from zero (black) to 100 (white).

\section{Results and discussion}

Figure 1 presents the $\mathrm{X}$-ray powder diffraction results of the alkaline earth-doped $\mathrm{CePO}_{4}$ pigments in comparison with that of pure $\mathrm{CePO}_{4}$. The single solid solution phase of 


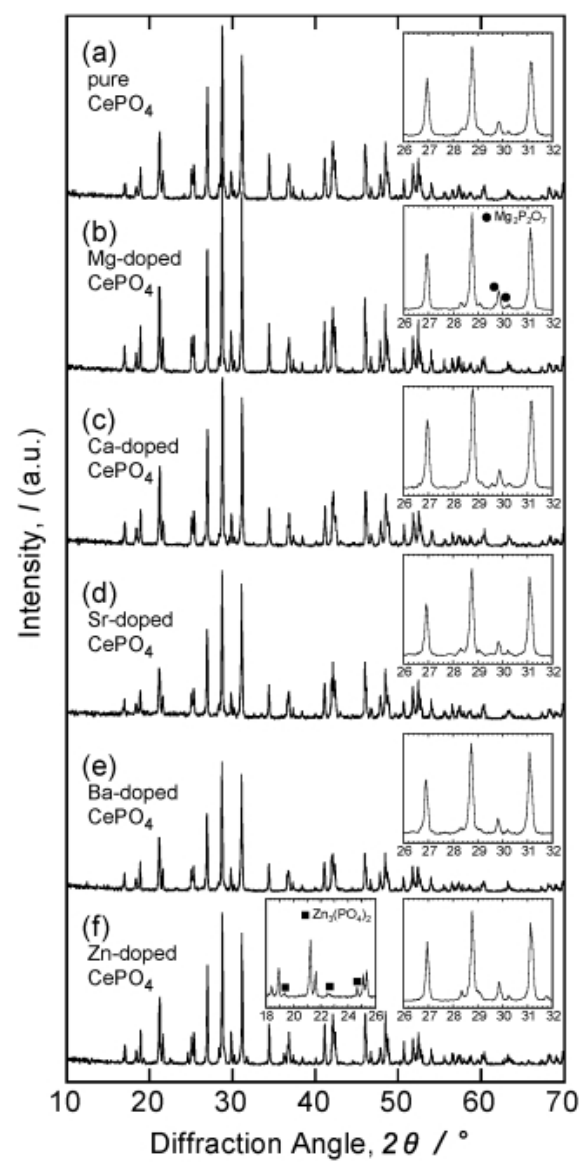

Fig. 1. X-ray powder diffraction patterns of (a) pure, (b) $\mathrm{Mg}$ doped, (c) Ca-doped, (d) Sr-doped, (e) Ba-doped, and (f) Zn-doped $\mathrm{CePO}_{4}$ samples.

$\mathrm{CePO}_{4}$ was obtained when $\mathrm{Ca}, \mathrm{Sr}$, or $\mathrm{Ba}$ was doped. The $\mathrm{CePO}_{4}$ has a monazite-type monoclinic crystal structure ${ }^{7), 8)}$ and the pattern shifted to higher angle by the $\mathrm{Ca}$ doping without any phase decompositions, while to lower angle by the $\mathrm{Sr}$ or Ba doping. Because the ionic radius of $\mathrm{Ce}^{3+}(0.120 \mathrm{~nm}$ for 9-coordinate $\left.{ }^{9)}\right)$ is larger than that of $\mathrm{Ca}^{2+}(0.118 \mathrm{~nm}$ for 9-coordinate $\left.{ }^{9)}\right)$ and is smaller than those of $\mathrm{Sr}^{2+}(0.131 \mathrm{~nm}$ for 9-coordinate $\left.{ }^{9)}\right)$ and $\mathrm{Ba}^{2+}\left(0.147 \mathrm{~nm}\right.$ for 9-coordinate $\left.{ }^{9)}\right)$, the X-ray results explicitly show that solid solutions were successfully obtained as a single phase by the replacement of the $\mathrm{Ce}^{3+}$ site for these ions. In contrast, in the cases for the $\mathrm{Mg}$ and $\mathrm{Zn}$ doping, no peak shift was observed in their XRD patterns and $\mathrm{Mg}_{2} \mathrm{P}_{2} \mathrm{O}_{7}$ and $\mathrm{Zn}_{3}\left(\mathrm{PO}_{4}\right)_{2}$ were produced as the secondary phases, respectively.

The XRD patterns for the reference $\mathrm{LaPO}_{4}$-based pigments are shown in Fig. 2 with that of pure $\mathrm{LaPO}_{4}$. Similar results to the $\mathrm{CePO}_{4}$ pigments were obtained, because the ionic radius of $\mathrm{La}^{3+}\left(0.122 \mathrm{~nm}\right.$ for 9-coordinate $\left.{ }^{9)}\right)$ is also larger than that of $\mathrm{Ca}^{2+}$ and is smaller than those of $\mathrm{Sr}^{2+}$ and $\mathrm{Ba}^{2+}$.

The color drastically changed from white to yellow-green by forming the solid solutions of Ca-, Sr-, and Ba-doped $\mathrm{CePO}_{4}$. The effect of alkaline earth doping on the color of the $\mathrm{CePO}_{4}$ based pigments was analyzed from the diffuse reflectance spectra depicted in Fig. 3. The Mg or Zn doping, because solid solutions are not produced with these dopants, did not affect the reflectance spectrum of $\mathrm{CePO}_{4}$. However, the reflectance spectra of the Ca-, Sr-, Ba-doped $\mathrm{CePO}_{4}$ shows a strong absorption band under $500 \mathrm{~nm}$ and a relatively small and

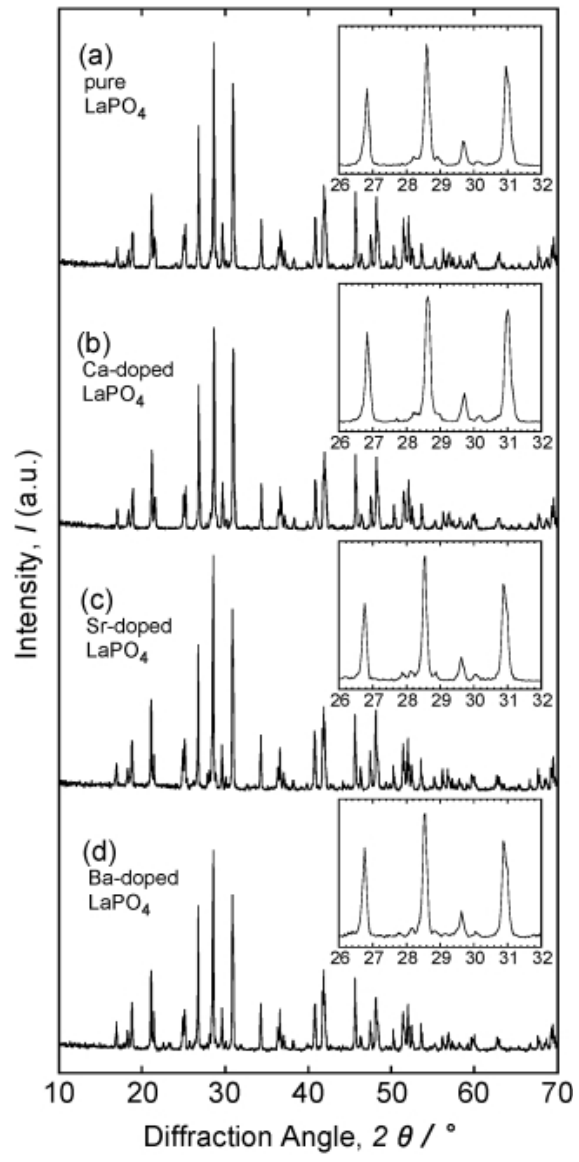

Fig. 2. X-ray powder diffraction patterns of (a) pure, (b) Cadoped, (c) Sr-doped, and (d) Ba-doped $\mathrm{LaPO}_{4}$ solid solutions.

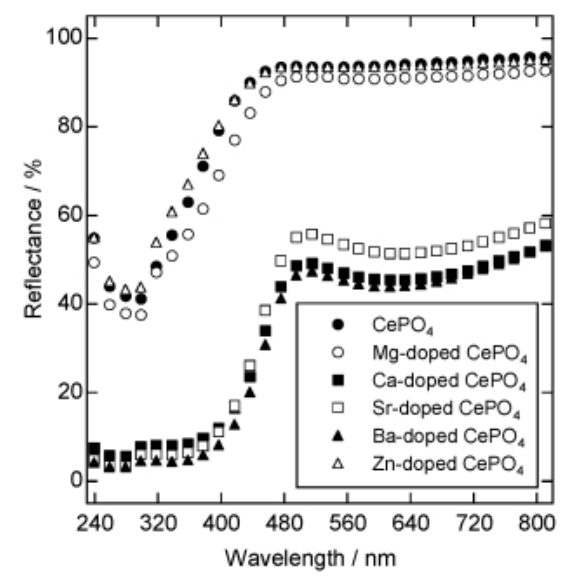

Fig. 3. Reflectance spectra for $\mathrm{CePO}_{4}$-based pigments.

broad peak at $600-650 \mathrm{~nm}$, compared with that of pure $\mathrm{CePO}_{4}$. These peaks imply some variation of the crystal field strength by the solution of alkaline metal ions into the $\mathrm{CePO}_{4}$ lattice. The change of the relative reflection intensities is responsible for the color change.

The $L^{*} a^{*} b^{*}$ color coordinate data of pure $\mathrm{CePO}_{4}$ and the $\mathrm{Mg}$-, $\mathrm{Ca}-, \mathrm{Sr}, \mathrm{Ba}-$, and $\mathrm{Zn}$-doped $\mathrm{CePO}_{4}$ pigments are summarized in Table 1. In this system, the $L^{*}$ values are indicative of color lightness, while $a^{*}$ and $b^{*}$ represent the level of red-green and yellow-blue components, respectively. As seen in Table 1, 
Table 1. Color Coordinate Values of the Pigments in the $L^{*} a^{*} b^{*}$ System

\begin{tabular}{lllll}
\hline Sample & $L^{*}$ & $a^{*}$ & $b^{*}$ & Color \\
\hline pure CePO & 95.5 & -0.54 & +1.25 & white \\
Mg-doped $\mathrm{CePO}_{4}$ & 96.0 & -0.54 & +1.67 & white \\
Ca-doped $\mathrm{CePO}_{4}$ & 72.9 & -8.08 & +13.7 & yellow-green \\
Sr-doped $\mathrm{CePO}_{4}$ & 73.4 & -8.91 & +15.9 & yellow-green \\
Ba-doped $\mathrm{CePO}_{4}$ & 68.1 & -8.30 & +14.1 & yellow-green \\
Zn-doped $\mathrm{CePO}_{4}$ & 97.2 & -0.53 & +1.96 & white \\
Pure LaPO $_{4}$ & 98.0 & -0.02 & +0.12 & white \\
Ca-doped $\mathrm{LaPO}_{4}$ & 99.7 & -0.47 & +1.22 & white \\
Sr-doped $\mathrm{LaPO}_{4}$ & 99.5 & -0.20 & +0.60 & white \\
Ba-doped $\mathrm{LaPO}_{4}$ & 99.1 & -0.36 & +0.92 & white \\
\hline
\end{tabular}
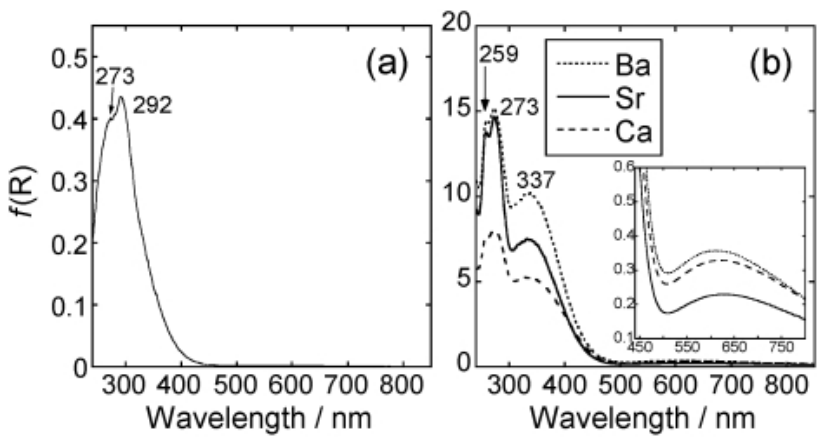

Fig. 4. Absorbance spectra of (a) pure $\mathrm{CePO}_{4}$ and (b) $\mathrm{Ca}-\mathrm{Sr}-$, or Ba-doped $\mathrm{CePO}_{4}$ pigments.

$L^{*}$ and $a^{*}$ decreased but $b^{*}$ increased by the formation of solid solutions with alkaline earths, indicating that the $\mathrm{CePO}_{4}$ based solid solution pigments have medium color lightness with the enhancement of green and yellow color. These results correspond to the above optical reflectance results.

The absorbance spectra of the white $\mathrm{CePO}_{4}$ and the yellowgreen $\mathrm{Ca}$-, $\mathrm{Sr}$-, or $\mathrm{Ba}$-doped $\mathrm{CePO}_{4}$ pigments represented with the remission function, $f(R)=(1-R)^{2} / 2 R$, are depicted in Fig. 4, where $R$ is reflectance. ${ }^{10), 11)}$ The weak absorption peaks are observed at 273 and $292 \mathrm{~nm}$ in pure $\mathrm{CePO}_{4}$. By the formation of solid solutions with alkaline earths, the peak at $273 \mathrm{~nm}$ splits into 259 and $273 \mathrm{~nm}$ and the intensity was drastically enhanced (compare the ordinate in Figs. 4(a) and (b)) and the peak at $292 \mathrm{~nm}$ shifted to longer wavelength $(337 \mathrm{~nm})$ with tailing its edge to $450 \mathrm{~nm}$. The magnitude of the enhancement of the former peaks was bigger than the latter. In addition, a new weak absorption peak appeared around 600-650 $\mathrm{nm}$ in every sample (the inset in Fig. 4(b)). Absorptions of the visible light at around 400-450 (purple and blue) and 600-650 nm (red) correspond to the appearance of yellow and green colors, respectively, because yellow is a complementary color to blue and green is the one to red.

In the case of $\mathrm{LaPO}_{4}$-based pigments, in contrast, the color almost unchanged even if the solid solutions were produced by the $\mathrm{Ca}, \mathrm{Sr}$, and $\mathrm{Ba}$ doping, as seen in the reflectance spectra in Fig. 5. The $L^{*} a^{*} b^{*}$ color coordinate data of the $\mathrm{LaPO}_{4}$-based pigments are also summarized in Table 1. Contrary to the results for the $\mathrm{CePO}_{4}$-based pigments, no effect is observed in their optical spectra and hue by the formation of the $\mathrm{LaPO}_{4}$ solid solutions with the alkaline earth ions. In order to identify a mechanism of the color appearance, FT-IR and Raman spectra for the $\mathrm{CePO}_{4}$ - and $\mathrm{LaPO}_{4}$-based pigments were characterized as shown in Figs. 6 and 7, respectively.

In the FT-IR spectra, the bands around 1110 (shoulder), 1092, 1070, 1020, 995, 954 (sharp), 627, 575, 560, and $538 \mathrm{~cm}^{-1}$ are assigned to the $\mathrm{PO}_{4}$ group in rare earth or-

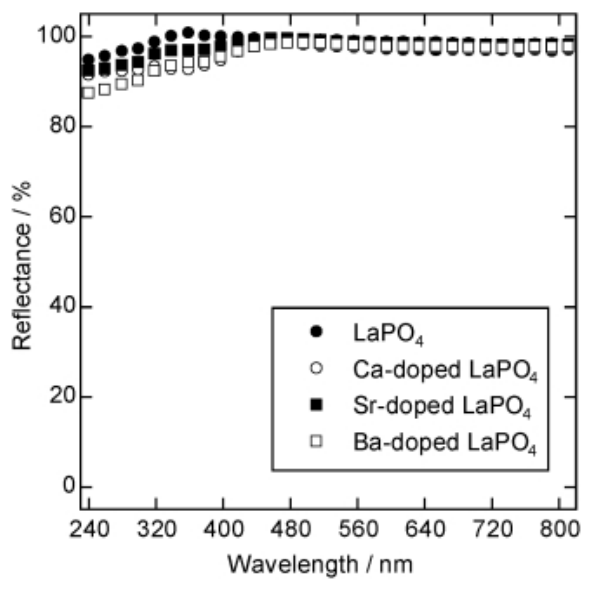

Fig. 5. Reflectance spectra for $\mathrm{LaPO}_{4}$-based solid solutions.

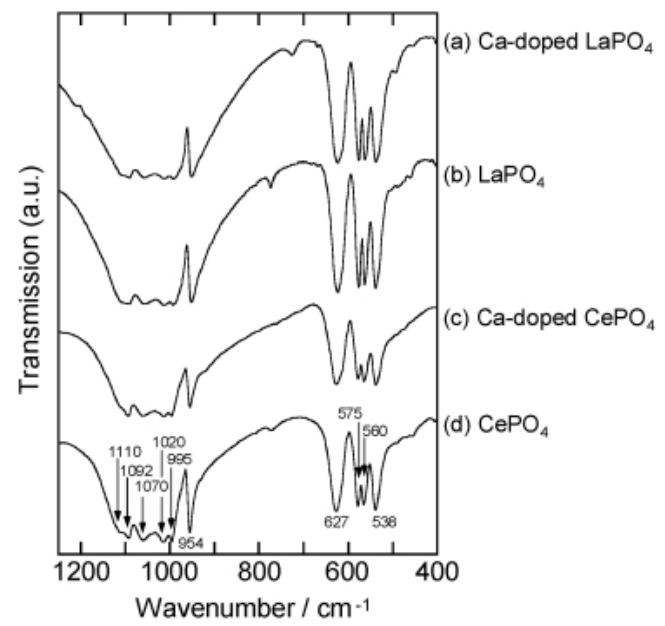

Fig. 6. FT-IR spectra of (a) Ca-doped $\mathrm{LaPO}_{4}$, (b) $\mathrm{LaPO}_{4}$, (c) Cadoped $\mathrm{CePO}_{4}$, and (d) $\mathrm{CePO}_{4}$.

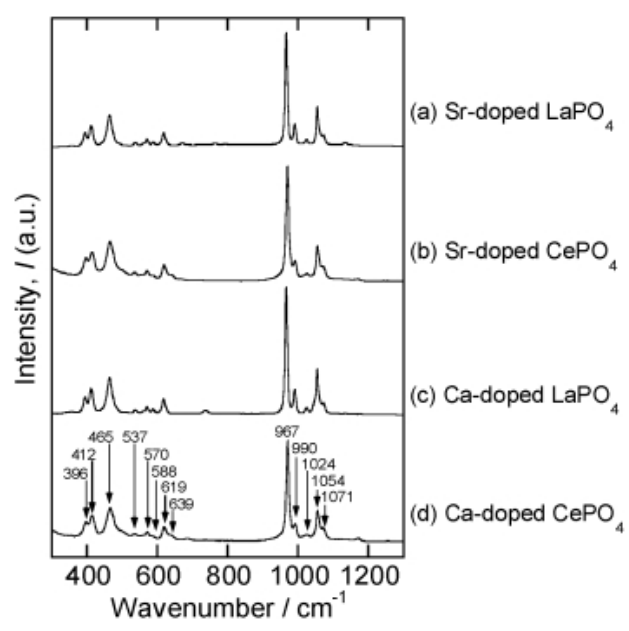

Fig. 7. Raman spectra of (a) Sr-doped $\mathrm{LaPO}_{4}$, (b) Sr-doped $\mathrm{CePO}_{4}$, (c) Ca-doped $\mathrm{LaPO}_{4}$, and (d) Ca-doped $\mathrm{CePO}_{4}$.

thophosphates. ${ }^{12), 13)}$ The bands at 1110, 1092, 1070, 1020, and $995 \mathrm{~cm}^{-1}$ are due to the asymmetric stretching of the $\mathrm{P}-\mathrm{O}$ bonds. The band at $954 \mathrm{~cm}^{-1}$ is assigned to symmetric stretch- 
ing vibrations of the $\mathrm{P}-\mathrm{O}$ bond, while four bands at 627,575 , 560 , and $538 \mathrm{~cm}^{-1}$ are attributed to asymmetric bending modes. In addition, the Raman spectra of all samples show the complementary bands at 396, 412, 465, 537, 570, 588, 619, $639,967,990,1024,1054$, and $1071 \mathrm{~cm}^{-1}$. The principal sharp band at $967 \mathrm{~cm}^{-1}$ is assigned to the symmetric stretching and those at 990 and $1024 \mathrm{~cm}^{-1}$ correspond to the asymmetric stretching of the $\mathrm{PO}_{4}$ group. The bands at 1054 and $1071 \mathrm{~cm}^{-1}$ are from the splitting of the asymmetric stretching mode and those from 396 to $639 \mathrm{~cm}^{-1}$ are attributed to the deformation mode of the $\mathrm{PO}_{4}$ group. ${ }^{14)}$ No clear differences are found between the spectra of the Ca- or Sr-doped $\mathrm{LaPO}_{4}$ and $\mathrm{CePO}_{4}$ pigments.

From the FT-IR and Raman results, the origin of the color change could be discussed from the change of $4 \mathrm{f}-5 \mathrm{~d}$ transition energy by the solution of alkaline earth ions into the $\mathrm{CePO}_{4}$ lattice accompanying the formation of oxide anion defects. In contrast to $\mathrm{LaPO}_{4}$, the reflectance spectrum of $\mathrm{CePO}_{4}$ exhibits a strong absorption band in the UV region due to the optically allowed $4 \mathrm{f}-5 \mathrm{~d}$ transition of cerium (Figs. 3 and 5), because $\mathrm{Ce}^{3+}$ has one $4 \mathrm{f}$ electron but there is no 4 f electron in $\left.\mathrm{La}^{3+} .{ }^{15}\right)$ The $4 \mathrm{f}-5 \mathrm{~d}$ transition is easily affected because $5 \mathrm{~d}$ orbitals are exposed to significant interaction with orbitals of surrounding atoms and ions in cerium orthophosphate. For example, strong absorption based on $4 \mathrm{f}-5 \mathrm{~d}$ transition has also been observed at around $450 \mathrm{~nm}$ in lithium cerium molybdate pigment to bring yellow hue. ${ }^{16)}$

In addition to the principal change of the $4 \mathrm{f}-5 \mathrm{~d}$ transition discussed above, the partial production of $\mathrm{Ce}^{4+}$ is also suggested, because it has been reported that cerium is in the tetravalent form in double cerium phosphates of $\mathrm{B}_{0.5} \mathrm{Ce}_{2}$ $\left(\mathrm{PO}_{4}\right)_{3}(\mathrm{~B}=\mathrm{Mg}, \mathrm{Ca}, \mathrm{Sr}$, and $\mathrm{Cd}) .{ }^{17)}$ By the formation of tetravalent cerium ion, the $\mathrm{O}_{2 \mathrm{p}}-\mathrm{Ce}_{4 \mathrm{f}}$ charge transfer transition also appears in the ultraviolet region and the $\mathrm{Ce}^{4+}$ produced affects the optical absorption of the $4 \mathrm{f}-5 \mathrm{~d}$ transition. The $4 \mathrm{f}-5 \mathrm{~d}$ transition correlates to the optical basicity which is modified by the partial oxidation of $\mathrm{Ce}^{3+}$ in the $\mathrm{CePO}_{4}$ lattice, and the basicity increases after the oxidation of $\mathrm{Ce}^{3+}$ to $\mathrm{Ce}^{4+}$ to induce the red shift in the optical reflection spectrum. ${ }^{18)}$ Thus, the absorption around $610 \mathrm{~nm}$ could be attributed to a increase of basicity of the pigment.

Taking into account of the above results, the reason for the color change can be attributed to the existence of $4 \mathrm{f}$ electron in $\mathrm{CePO}_{4}$ and combination of the main $4 \mathrm{f}-5 \mathrm{~d}$ and the additional $\mathrm{O}_{2 \mathrm{p}}-\mathrm{Ce}_{4 \mathrm{f}}$ charge transfer accompanying with the partial red shift of the former transition. Therefore, the remarkable color changes were observed in the $\mathrm{CePO}_{4}$ solid solution pigments, while no color change appeared the $\mathrm{LaPO}_{4}$-based pigments.

\section{Conclusion}

From the results discussed above, it can be concluded that the doping of divalent alkaline earth ions into the $\mathrm{CePO}_{4}$ lattice induce not only the change of $4 \mathrm{f}-5 \mathrm{~d}$ transition energy but also the partial oxidation of cerium ion. By combination of the principal $4 \mathrm{f}-5 \mathrm{~d}$ transition of $\mathrm{Ce}^{3+}$ and the additional $\mathrm{O}_{2 \mathrm{p}}-\mathrm{Ce}_{4 \mathrm{f}}$ transition of $\mathrm{Ce}^{4+}$, the color of the cerium phosphate changes from white to yellow-green. In the case of $\mathrm{LaPO}_{4}$, on the contrary, such effects are not observed because there is no $4 \mathrm{f}$ electron in this compound. More studies on possible applications of these powders as pigments in plastics and paints should be performed. However, the properties of the present $\mathrm{Ca}-, \mathrm{Sr}-$, or Ba-doped $\mathrm{CePO}_{4}$ solid solutions suggest that this material has a potential to be applied as a satisfactory pigment for coating, because these pigments have advantages from the viewpoint of environmental pollution, compared with conventional toxic green pigments commercially applied.

Acknowledgements The authors sincerely thank Dr. Kuniaki Murase and Prof. Yasuhiro Awakura (Kyoto University) for their assistance with the Raman spectra measurements. The 21st COE Research Grant "Integrated EcoChemistry" supported this work for young researchers. This work was also partly supported by the Industrial Technology Research Grant Program in '02 (project ID: 02A27004c) from the New Energy and Industrial Technology Development Organization (NEDO) based on funds provided by the Ministry of Economy, Trade and Industry, Japan (METI).

\section{References}

1) Smith, H. M. (Ed.), "High Performance Pigments," WileyVCH Verlag-GmbH, Weinheim (2002) pp. 3-73.

2) Jansen, M. and Letschert, H. P., Nature, Vol. 404, pp. 980-982 (2000).

3) Trojan, M., S̆ulcová, P. and Mošner, P., Dyes Pigments, Vol. 44, pp. 161-164 (2000).

4) Sulcová, P. and Trojan, M., Thermochim. Acta, Vol. 395, pp. 251-255 (2003).

5) Rao, P. P. and Reddy, M. L. P., Dyes Pigments, Vol. 63, pp. 169-174 (2004).

6) Imanaka, N., Masui, T. and Itaya, M., Chem. Lett., Vol. 32, pp. 400-402 (2003).

7) Miyawaki, R. and Nakai, I., Kidorui, Vol. 11, pp. 1-133 (1987).

8) Ni, Y., Hughes, J. M. and Mariano, A. N., Am. Mineral., Vol. 80, pp. 21-26 (1995).

9) Shannon, R. D., Acta Crystallogr., Vol. A32, pp. 751-767 (1976).

10) Eppler, D. R. and Eppler, R. A., Ceram. Eng. Sci. Proc., Vol. 17, pp. 77-87 (1996).

11) Kato, M. and Takahashi, M., J. Mater. Sci. Lett., Vol. 20, pp. 413-414 (2001).

12) Hezel, A. and Ross, S. D., Spectrochim. Acta, Vol. 22, pp. 1249-1961 (1966).

13) Lucas, L., Champion, E., Penot, C., Leroy, G. and BernacheAssollant, D., Key Eng. Mater., Vol. 206-213, pp. 47-50 (2002).

14) Begun, G. M., Beall, G. W., Boatner, L. A. and Gregor, W. J., J. Raman Spectrosc., Vol. 11, pp. 273-278 (1981).

15) Riwotzki, K., Meyssamy, H., Kornowski, A. and Haase, M., $J$. Phys. Chem. B., Vol. 104, pp. 2824-2828 (2000).

16) Odaki, T., Hashimoto, K., Yoshida, K. and Toda, Y., Shikizai Kyokaishi, Vol. 75, pp. 261-266 (2002) [in Japanese].

17) Orlova, A. I., Kitaev, D. B., Volkov, Y. F., Pet'kov, V.I., Kurazhkovskaya, V. S. and Spiridonova, M. L., Radiochemistry, Vol. 43, pp. 225-228 (2001).

18) Chen, G., Baccaro, S., Nikl, M., Cecilia, A., Yang-Du, Y. and Mihokova, E., J. Am. Ceram. Soc., Vol. 87, pp. 1378-1380 (2004). 